\title{
O uso da língua como fator para a (re)afirmação da identidade étnica: experiências em Colônia Witmarsum
}

\author{
Carla Caroline Holm* \\ Poliana Fabíula Cardozo**
}

\begin{abstract}
Resumo
Este artigo apresenta uma das possibilidades para caracterização da identidade étnica, sendo o uso da língua materna por sujeitos migrantes. O objetivo geral é analisar a importância do uso da língua materna para a (re)afirmação da identidade étnica em Colônia Witmarsum, localizada em Palmeira/PR cuja composição é de alemães menonitas que migraram para o Brasil no século XX. Por meio de pesquisa bibliográfica abordando os temas cultura, identidade, e etnicidade e também utilizando-se de pesquisa de campo, com a realização de entrevistas direcionadas de roteiro semiestruturado, foi possível compreender a identidade étnica manifestada de diferentes formas nesta comunidade. A partir de análise de conteúdo, atingiu-se o objetivo proposto aqui que trata do uso da língua. Desta maneira, o presente artigo traz um exemplo de possibilidade de manifestação da identidade étnica na comunidade de estudo a fim de reconhecer a legitimidade desta ação como contribuinte para a preservação da cultura local.

Palavras-chave: cultura, imigração, identidade étnica, uso da língua, Colônia Witmarsum.
\end{abstract}

\section{The use of the language as a factor for (re)statement of ethnic identity: experiences in Colônia Witmarsum}

\begin{abstract}
This article presents one of the possibilities for characterization of ethnic identity, and the use of the mother tongue by migrant subjects. The overall objective is to analyze the importance of using the mother tongue for the (re) affirmation of ethnic identity in Colônia Witmarsum, located in Palmeira/PR whose composition is of Mennonite Germans who migrated to Brazil in the twentieth century. By means of literature addressing the themes of culture, identity and ethnicity and also using field research with interviews directed to semi-structured was possible to understand the ethnic identity manifested in different ways in this community. From content analysis, it was reached the goal proposed here, that is, the language use. Thus, this article brings a manifestation of the possibility of example of ethnic identity in the study community to recognize the legitimacy of this action as contributing to the preservation of local culture.
\end{abstract}

Keywords: culture, immigration, ethnic identity, language use, Colônia Witmarsum

\section{Introdução}

A cultura tem se mostrado uma temática de estudo complexa por tratar de um fenômeno social e humano presente no cotidiano e que está em constante mudança a fim de se adaptar às transformações do mundo. Os sujeitos formadores da cultura humana deslocam-se ao redor do mundo visando por meio disto ter suas necessidades atendidas, adaptando-se assim aos novos contextos que encontram. Junto desta mudança territorial existem novos hábitos que são incorporados em seu cotidiano e, por isto, a cultura transforma-se de acordo com o meio em que as pessoas passam a habitar.

Todavia, existem características inerentes à cultura de origem destas pessoas que permanecem independentes da mudança territorial ocorrida, pois é por meio disto que os indivíduos representam suas raízes e se identificam com os seus semelhantes. Esta manutenção de ações ligadas à cultura de origem denomina-se identidade étnica, sendo por meio destas manifestações que as pessoas passarão a identificar-se, a sentirem-se unidas e aceitas, mesmo quando passam a pertencer a um espaço territorial diferente do seu de origem.

Dito isto, o objetivo deste trabalho é analisar a importância do uso da língua materna para a (re)afirmação da identidade étnica em Colônia Witmarsum, localizada em Palmeira/PR. A escolha da temática se dá em virtude do local de estudo ser composto por imigrantes e descendentes 
de alemães menonitas ${ }^{1} \mathrm{e}$, mesmo não havendo um fluxo migratório contemporâneo, eles mantém traços identitários relacionados à etnicidade alemã.

Colônia Witmarsum está localizada acerca de $60 \mathrm{Km}$ da capital do estado do Paraná, Curitiba, e foi formada a partir da (re)imigração de alemães menonitas no ano de 1951 (ASSOCIAÇÃO COMUNITÁRIA DOS MORADORES PROPRIETÁRIOS DE WITMARSUM - ACPMW, 2014; KLOSTER, 2013; SOARES, 2013). Nesta comunidade, são preservados traços da cultura alemã no que dizem respeito à gastronomia, história, vestimentas, manifestações artísticas, bem como fortemente o uso da língua alemã oficial e do dialeto denominado Plautdietsch ${ }^{2}$. Assim, percebese que estes formam e/ou representam o patrimônio étnico da comunidade e por consequência compõe sua identidade.

Para a estruturação deste trabalho realizouse consulta bibliográfica sobre os temas relacionados à cultura, identidade e etnicidade, buscando neles subsídios necessários para a compreensão teórica do assunto proposto. Posterior a isto, foram efetuadas visitas na comunidade objeto para a observação da realidade vivida no local e, como método complementar para fornecer respostas a esta pesquisa, foram realizadas entrevistas com moradores da colônia, cujo tema condutor nesta etapa foi a importância do uso da língua materna como um fator identitário.

A partir disto, este trabalho divide-se em cinco momentos, sendo o primeiro e o segundo dedicados à discussão científica dos temas relevantes, a saber: cultura, etnicidade, identidade étnica e uso da língua por sujeitos imigrantes e/ou descendentes de imigrantes. A terceira parte apresenta a comunidade, assim como as atividades naquele local desenvolvidas. Disto segue-se uma descrição e análise das entrevistas realizadas com moradores, que fazem referência ao uso da língua alemã e dialeto Plaudietsch; e por fim, a última parte apresenta uma reflexão sobre a identidade étnica mantida por meio do uso da língua em território que não o de origem de um grupo.

\section{Cultura e identidade étnica: duas faces de uma mesma moeda}

Tratar de cultura e suas representações sociais é um trabalho que envolve a subjetividade do sujeito a quem se refere, pois não há um padrão a ser seguido ou tampouco um único elemento que represente a cultura de um povo. A cultura é tratada de forma ampla, pois sua definição é subjetiva e nunca reducionista. Ela pode ser definida como um conjunto de valores e ações determinados pela sociedade em que o sujeito habita, ou seja, não é algo pré-determinado pelo histórico biológico ou por herança genética.

Ela é tratada de forma distinta variando de acordo com a realidade em que os sujeitos estão inseridos. Para Tylor (1871 apud LARAIA 2007, p. 25), a cultura pode ser compreendida como “(...) este todo complexo que inclui conhecimentos, crença, arte, moral, leis, costumes ou qualquer outra capacidade ou hábitos adquiridos pelo homem como membro de uma sociedade". Desta maneira, nota-se que a cultura é ampla e não se restringe a uma manifestação única, ela transforma-se junto com o tempo e contribui para que a sociedade se construa e se modifique a partir das intervenções humanas.

Segundo a Organização das Nações Unidas para a Educação, a Ciência e a Cultura (UNESCO) (1982, p. 39, tradução nossa ${ }^{3}$ ), a cultura engloba “(...) as artes, as letras, os modos de vida, os direitos fundamentais ao ser humano, os sistemas de valores, as tradições e as crenças.". Deste modo, pode-se compreender a cultura como sendo um fenômeno expressivo na sociedade, pois nela as pessoas podem basear-se para construir suas vidas e suas crenças. Neste sentido, ela é compreendida para além de objetos e manifestações eruditos, tratando também das manifestações consideradas por vezes ordinárias como a língua, por exemplo.

Para Claval (2001, p.13), "as culturas são realidades mutáveis" e, neste sentido, fazem parte da cultura uma miríade de possibilidades de identificação entre os grupos de indivíduos. Possibilidades estas que variam de acordo com o meio em que os grupos estão instalados e com a realidade em que encontram neste espaço. Pode-se afirmar, portanto, que a cultura é um legado herdado, no entanto, transforma-se e adapta-se mesmo que haja deslocamento de membros destes grupos ao redor do mundo.

Além da cultura, interessa a essa discussão as noções de identidade cultural, as quais para Zugueib (2005), oferecem ao sujeito significações históricas e sociais que lhe servem como referências e orientações acerca dos valores e modelos que encorajam a produção de sentidos, comportamentos e das representações na sua etnicidade.

A identidade cultural manifesta-se nos contextos de diferença, ou seja, em ambientes e 
situações em que o sujeito não está entre seus semelhantes e, de maneira instintiva, demonstra suas origens e raízes. Isso porque se o entendimento de identidade é o que se é, só se percebe o que se é ao estar em situação de contraste. Para Cardozo (2012), as pessoas percebem suas diferenças quando entram em contato com o outro, comparando-se com os demais e o modo com que estes conduzem suas vidas. "A identidade cultural se forma principalmente em elementos diferenciados (...) a ideia de uma origem comum; e a construção da pessoa baseada na articulação assumida de todos os aspectos da vida ao redor dos valores centrais da cultura" (CARDOZO, 2012, p. 37). Já Claval (2007) destaca três componentes, que concorrem para a formação das identidades culturais: a vontade de se conformar aos usos de um grupo; a ideia de uma origem comum; e a construção da pessoa baseada na articulação assumida de todos os aspectos da vida ao redor dos valores centrais da cultura.

No que diz respeito à construção da identidade, segundo Cuche (2002), passa pela relação entre grupos diferentes. Com apoio em Barth, o relevante não seria inventariar as marcas culturais distintivas, mas sim determinar aquelas que são utilizadas pelo grupo "para afirmar e manter uma distinção cultural” (CUCHE, 2002, p. 182). A identidade seria construída e reconstruída a todo o momento reunindo o construto e a construção: objeto e processo.

Levando a discussão para o tema da etnia e etnicidade, a origem da palavra etnia teria se dado dentro das quatro raízes das línguas ocidentais: o indo-europeu; o berbere; o árabe, e o turco. $\mathrm{O}$ indoeuropeu teria tido, entre outras, a influência do sânscrito de onde proviria o vocábulo svadha, que pressupõe "consciência individual"; daí teria avançado para hábito e comportamento, não só pessoal, como também tribal. A partir do grego mais arcaico, svadha transformou-se em svethos, de onde evoluiria para ethos e ethnos, ética e etnia. (SANTAYANA, 2002). Nesses termos, olhar a etnia como fonte de identidade, significa considerar outros estilos de vida como fonte de identidade, tais como gênero e religiosidade. Santayana (2002, p.325) reflete sobre a identificação das etnias, afirmando que o primeiro traço seria a "associação dos grupos humanos com o espaço que ocupam" e outros traços poderiam ser identificados, tais como: "a língua, os costumes, os instrumentos da vida, mas todos eles, como sabemos, amarrados, de uma forma ou de outra, ao espaço circundante, que, sendo a extensão da consciência, é o oikos, a casa".

Nesse sentido, Poutignat e Streiff-Fenart (1998, p. 24) explicam que o termo etnicidade designaria "não a pertença étnica, mas os sentimentos que lhe estão associados: o sentimento de formar um povo [...] partilhado pelos membros de subgrupos no interior das fronteiras nacionais". É dizer que, a etnicidade extrapolando as fronteiras nacionais, pode ser encarada não apenas como característica cultural de um povo em seu país de origem, contudo, também aos que imigraram, ou receberam sua influência por meio de invasões e possessões, mas que, de alguma maneira, sobrevive à supremacia de uma cultura nacional diferente da expressa. Inclusive, as características culturais, quando ultrapassam as fronteiras nacionais e se fazem presentes em terras longínquas, mesmo sofrendo alterações ao longo do processo de reenraizamento podem continuar a demarcar uma etnicidade.

A identidade étnica é uma das identidades possíveis, ela faz referência à identificação com a cultura de um local específico. Para Silva e Carvalho (2010, p. 208) ela:

é o alicerce para a sua forma de organização, para sua relação com os demais grupos e de seu agir político. A atitude pela qual os grupos sociais definem o próprio pertencimento é resultado de uma confluência de fatores determinados por eles mesmos, no qual constam itens como a ancestralidade comum, formas de organização política e social, elementos linguísticos e religiosos.

Neste sentido, fazem parte desta identidade todas as manifestações de cultura relacionadas com um local de origem e com isto é possível dizer que incorporam outros elementos como a gastronomia, a vestimenta e os adornos, por exemplo. A identidade étnica é um sentimento de vinculação e pertencimento com um grupo e ainda ela está em reconstrução a todo o momento.

A etnicidade, que compõe a identidade, é uma maneira dos sujeitos perceberem o mundo, pois está carregada de elementos que alteram-se de acordo com o meio em que estão inseridos. A etnicidade está relacionada diretamente à identidade de um grupo, ela “(...) é essencialmente a forma de 
interação entre grupos culturais, operando dentro de contextos sociais comuns (...)" (COHEN, 1974 apud CARDOSO DE OLIVEIRA, 2006, p. 23). Ainda para o autor,esta identidade fortalece os laços entre os semelhantes, de modo a garantir que esta união venha assegurar autodefesa em possíveis situações de conflitos. Para ele, “(...) a identidade étnica agrupa, agrega, unifica, malgrado a diferença os ecossistemas e, com eles, a presença de alguma variação cultural interna à etnia" (CARDOSO DE OLIVEIRA, 2006: 38).

Para Grünewald (2003, p.145), a etnicidade é um fenômeno social de identificação coletiva, cuja utilidade é “(...) caracterizar um grupo étnico, devese remeter a noções de origem história, cultura e, até raça comuns". Desta maneira, o sujeito se reconhece dentro de um grupo étnico por estar tratando interesses partilhados e ainda tal identidade serve para auto-representação ou de representação para os que deste grupo cultural não fazem parte. Logo, é possível afirmar a similitude existente entre a identidade e a etnicidade, de modo que ambas referem-se a interesses coletivos relacionados à cultura e mais que isto, é possível perceber a relação estreita entre a cultura e a identidade étnica dos grupos.

\section{O uso da língua materna por imigrantes: construções identitárias e o sentimento de pertencimento}

Os deslocamentos migratórios são fenômenos cada vez mais comuns na atualidade e nota-se que as motivações destes são cada vez mais distintas, todavia como já descrito, alguns traços étnicos acompanham os sujeitos migrantes e os caracterizam como um grupo distinto no país receptor (CARDOZO, 2012). Manter estes elementos é uma das maneiras de preservar a cultura de origem e identidade das pessoas e, para isto, existem algumas características que se sobressaem e não sofrem transformações ao longo do tempo. Mesmo a cultura sendo mutável, como afirmado por Claval (2001), existem elementos que servem de pilar fundamental dos grupos migrantes, a língua, objeto desta pesquisa, pode ser um exemplo.

Nos estudos de Cardozo (2012) sobre a presença de libaneses em Foz do Iguaçu, a relação com a língua mesmo fora do país de origem do grupo migrante pode ser percebida de forma clara, na qual os seus entrevistados afirmam sentir-se mais a vontade utilizando a língua materna. Para a autora, "elementos como idioma e religião podem auxiliar ao mantenimento das tradições culturais, pois são elementos propícios para a (re)construção da identidade cultural de uma comunidade de imigrantes" (CARDOZO, 2012: 121).

Desta forma, percebe-se que algumas características são estruturantes culturais, haja vista o sentimento de pertencimento e construção constante da identidade étnica. Tais diferenciais podem ser observados em várias outras comunidades migrantes que não a estudada nesta pesquisa.

As marcas culturais podem ser visualizadas em muitos outros aspectos, como a gastronomia, a arquitetura, a música, as danças e outras tantas. Contudo, pode-se notar que o fator linguístico caracteriza grupos migrantes por ligar aqueles que tiveram que partir com aqueles que ficaram na terra de origem. Para Cardozo (2012), quando um grupo de migrantes faz o uso da língua materna em seu cotidiano e deseja repassar este patrimônio às gerações vindouras, os laços com a cultura podem ser e são mantidos a partir também desta manifestação. Segundo ela, "romper com a origem e se entregar totalmente ao novo é quase impossível: a cultura de origem lhe é fundante, lhe ensinou o certo e o errado, lhe mostra os valores a serem perseguidos..." (CARDOZO, 2012, p. 136).

O caso dos menonitas é singular porque eles apresentam-se como um grupo que não possui um território de origem fixo. Como são sujeitos pertencentes a um movimento religioso, o apego à cultura alemã e ao uso do alemão oficial ou do dialeto em seu cotidiano se dá em virtude do local de origem da história do grupo e manter esta cultura viva é uma das formas de permanecer em contato com toda uma história de vida que ficou para trás.

Para os sujeitos migrantes, a vida no país receptor é um constante "lá" e "aqui", pois considera-se o fato de não conseguir mais ficar no país de origem (por motivos distintos) e tampouco esquecer as raízes do grupo cultural a que pertencem. Com base em Poutignat e Streiff-Fenart (2011), é possível afirmar que para compreender a identidade étnica destes migrantes faz-se necessário admitir que existem fronteiras baseadas sempre no Nós/Eles e estas fronteiras existem devido às diferenças culturais. Estas diferenças são assumidas como estereótipos do grupo, o que permite julgar quem faz parte do "nós" e quem faz parte do "eles" e também admitir que algumas características culturais são fixas e que, desta forma, asseguram 
uma identidade étnica a um grupo percebido em contexto de diferença.

\section{Colônia Witmarsum: compreendendo a comunidade e a manutenção cultural por meio da presença de elementos étnicos}

Formada por reimigrantes ${ }^{4}$ vindos principalmente do norte da Alemanha, a Colônia Witmarsum é uma das colônias de menonitas estabelecidas na América do Sul cuja motivação da migração foi a perseguição sofrida por este grupo na Rússia durante o século XX (ACPMW, 2001; ENNS; CAMARGO; KRÜGER, 2000; PAULS, 2010).

A comunidade teve sua origem nos anos 1930 quando chegaram as primeiras levas de menonitas refugiados da Rússia no Brasil. Formouse primeiramente uma pequena cidade denominada Witmarsum em Santa Catarina cujo nome homenageia a cidade alemã de MennoSimons ${ }^{5}$ e vinte anos mais tarde em virtude das condições do solo infértil, estes imigrantes mudaram-se para o Paraná. Neste último deslocamento, os destinos foram Curitiba e a então Fazenda Cancela em Palmeira/PR localizada acerca de $60 \mathrm{Km}$ da capital, onde localiza-se atualmente a Colônia Witmarsum (ENNS; CAMARGO; KRÜGER, 2000).

Tão logo instalaram-se na Fazenda Cancela em 1951, os alemães menonitas organizaram-se e montaram a Cooperativa Agropecuária de Witmarsum Ltda, de modo que esta se responsabilizaria pela administração e comercialização dos produtos fabricados na comunidade, tais como: leite e derivados, frangos de corte, milho, soja, trigo, etc. (ACMPW, 2001; WITMARSUM COOPERATIVA, 2014). Contudo, segundo Kloster (2013) e Soares (2013), acompanhados de relatos de membros da comunidade, a partir dos anos 2000 passou a agregar a economia local o desenvolvimento da atividade turística ainda que não organizada, por meio da construção de pousadas, restaurantes e cafés, primeiramente visando atender às necessidades dos negociantes motivados pela cooperativa agrícola local.

Para a ACMPW (2001, p. 11), "Localizada em região geograficamente privilegiada e possuindo tradição e cultura para apresentar aos visitantes, o turismo é uma fonte alternativa de receita." Atualmente a atividade tem ganhado expressão no local, haja vista que o número de visitantes tem crescido, bem como os investimentos no setor. Desta maneira, percebe-se a presença de duas atividades econômicas centrais, sendo a cooperativa a grande geradora de emprego e renda para as famílias que lá vivem e depois dela o turismo que possibilitou a inclusão de pessoas que por motivos diversos ainda não estavam ligadas ao mercado de trabalho formal.

Hoje vivem na Colônia de Witmarsum cerca de 300 famílias de alemães, sendo que totalizam uma média de 2000 pessoas, segundo informações obtidas nas entrevistas e constantes em Kloster (2013). Destas, estima-se que 1200 sejam alemães menonitas praticantes e 800 não menonitas. Ainda estão vivos, dos colonizadores alemães, cerca de 15 pessoas que têm em média 80 anos de idade.Os elementos culturais étnicos que estão presentes na comunidade são a história de vida dos imigrantes e da imigração menonita ao redor do mundo, a gastronomia típica, algumas construções arquitetônicas, o modo de vida e trabalho, a vestimenta, a religião, música e sobretudo o uso da língua alemã oficial e dialeto Plautdietsch.

Em relação a este último, foco principal desta pesquisa, nota-se que o português é utilizado em ocasiões específicas cuja presença de não membros da comunidade é expressiva. Além desses momentos, as línguas de comunicação entre os moradores é o alemão oficial e o dialeto.

\section{Entre Brasil e Alemanha: construção de identidades plurais em Colônia Witmarsum}

Para compreender a identidade étnica dos moradores de Colônia Witmarsum a partir do uso da língua materna, foram realizadas visitas no local de estudo e também entrevistas com moradores da comunidade. Neste momento da pesquisa, o nome dos entrevistados foi alterado buscando preservar suas identidades. Para o cumprimento do objetivo central, utilizou-se um roteiro de entrevista semiestruturado para conduzir a coleta de informações. Para responder ao roteiro de entrevista elaborado, a escolha dos sujeitos se deu de maneira aleatória e os entrevistados serão denominados como Albert e Kristen (60 e 32 anos, respectivamente). Julgou-se pertinente a escolha destes dois participantes, haja vista a diferença geracional, de modo a garantir respostas de públicos com perspectivas distintas.

Segundo Cardozo (2012), utilizar-se da língua materna é algo crucial para imigrantes e 
descendentes que desejam manter-se relacionados com a cultura de origem do seu grupo. Ainda para a autora utilizar a língua como uma ferramenta de seu cotidiano é uma das formas encontradas para que o grupo migrante se mantenha unido ao seu local de origem.

Para Poutignat e Streiff-Fenart (2011, p. 38): “A língua e a religião desempenham um papel importante, talvez porque elas autorizam a comunidade de compreensão entre aqueles que compartilham um código linguístico comum ou um mesmo sistema de regulamentação ritual da vida".

Com isto, pode-se dizer que estas características culturais étnicas fortalecem o sentimento de pertencimento a um grupo, haja vista a identificação com pessoas que compartilham de uma mesma origem e de uma mesma história. Neste sentido, percebe-se que a temática aqui tratada mostra-se importante, considerando-se que discute o comportamento dos sujeitos migrantes a partir de um ato rotineiro e, por vezes, considerado ordinário. Isso porque o comunicar-se é algo que passa despercebido quando as pessoas encontram-se inseridas em seus grupos.

Comunicar-se, neste caso é para além de transmitir uma mensagem. Para os sujeitos frutos de deslocamentos migratórios, comunicar-se utilizando-se do idioma materno é estar relacionado com suas origens e um modo de sentirem-se mais alemães, como o caso deste estudo.Desta maneira, quando questionados sobre quais são os elementos que caracterizam a cultura e a identidade alemã dentro da colônia, ambos entrevistados relataram que a língua em primeiro lugar e posterior a ela, a gastronomia, a história de vida e imigração, a religião e a música.

A partir da inclusão da língua como um elemento caracterizador da identidade étnica, a entrevista teve como foco o uso desta na vida dos sujeitos representantes da comunidade.

Albert durante a entrevista afirma

O mais forte em nosso cotidiano é o uso da língua, nós mantemos porque é o que dá a nossa identidade. Esta é a relação que todo o migrante tem com a sua história e sempre que falamos na nossa língua mãe, mesmo que inconsciente, estamos falando dos nossos antepassados, das lutas que aconteceram para chegarmos até onde estamos e também nos sentimos bem quando falamos na nossa língua... Falamos em Plat como uma forma de lembrar que pertencemos a este grupo, temos uma identidade comum e enquanto falo eu não penso nisso, não penso na minha identidade a todo momento, sou o que sou...

Pode-se perceber, que a língua é mais do que simples comunicação, ela remete à história do grupo e faz com que a cultura seja reafirmada nas manifestações mais simples.

No que diz respeito aos momentos em que a língua é utilizada, ambos relataram que o alemão oficial é utilizado na igreja, na escola, nas negociações entre os membros da colônia e quando em contato intergeracional, visto que os colonos de primeira e segunda geração possuem maior afinidade com o dialeto Plaudietsch e o alemão oficial. Ao passo que a partir da terceira geração as pessoas comunicam-se melhor utilizando-se do alemão oficial e o português.

Sobre a importância da continuidade do uso da língua na comunidade como um elemento que caracteriza da identidade étnica, os entrevistados afirmam que é uma forma de sempre se lembrarem de onde vieram e porque estão aqui, levando em consideração toda a história das diversas migrações que o povo alemão menonita já vivenciou.

Kristen ainda afirma que

É uma forma de sempre estarmos ligados com o nosso local de origem. Embora não tenhamos uma pátria definida, a nossa pátria de coração é o Brasil, mas as nossas raízes estão na Alemanha (...) Usar a língua alemã nos remete a um sentimento de pertença e de identidade, embora saibamos que não somos de fato alemães, mas usando a língua das nossas raízes, nos sentimos um pouco mais alemães.

Percebe-se que o uso da língua materna para eles, além de simplesmente comunicar-se, é também uma maneira de fazer referência a sua identidade étnica. Quando questionados sobre o aprendizado da língua oficial e do dialeto, para fortalecer os laços entre os moradores da comunidade e suas famílias, os entrevistados responderam que fazem questão de ensinar estas línguas para as gerações que estão chegando. E ainda, para além disto, praticam em 
todos os momentos do dia, pois compreendem que é desta forma que os jovens aprenderão, praticarão e se sentirão incluídos como alemães menonitas, ainda que a pátria a que pertencem seja o Brasil.

Em relação a este ponto especificamente, os entrevistados afirmam que muitos dos moradores da comunidade possuem pontos de vista distintos em relação à sua pátria. Muitos afirmam ser alemães, outros tantos dizem ser brasileiros e ainda há quem diga ser alemão-abrasileirado. No entanto, todos reconhecem suas raízes, sua formação e a condição em que se encontram, mesmo que este reconhecimento se dê de maneira distinta em cada caso.

Dito isto, pode-se assegurar que o uso da língua alemã oficial ou ainda o dialeto Pautdietch é um importante pilar para a composição cultural dos moradores da colônia. Uma vez que os imigrantes e seus descendentes sentem-se confortáveis e até "mais alemães", como foi dito por Kristen, utilizando-se da língua do país a que o grupo teve origem. Nota-se que independente do espaço que ocupam, a identidade étnica é fortemente representada por elementos alusivos à sua história $\mathrm{e}$ cultura.

Isto posto, pode-se afirmar que preservar estes traços identitários nas gerações vindouras e cada vez mais inseridas num meio distinto ao de origem é talvez um dos desafios desta e de outras comunidades de imigrantes ao redor do mundo, todavia, este é um debate para outro momento. Não se pode afirmar que a identidade seja para sempre representada pelos mesmos objetos e sentimentos. No entanto, neste estudo apresentado, o uso da língua alemã, seja em sua forma oficial ou dialeto, é um eixo estruturante da cultura alemã menonita localizada em Colônia Witmarsum.

\section{Considerações finais}

$\mathrm{O}$ ato de imigrar tem se tornado cada vez mais frequente na atualidade e os motivos são diversos, todavia, o que pode ser percebido é que mesmo com grandes descolamentos ao redor do mundo, o sentimento de pertença e construção de identidades étnicas por sujeitos migrantes se repetem independente da origem destes sujeitos. Tais manifestações alusivas à identidade étnica são múltiplas, sejam elas relacionadas aos valores familiares, modo de vida, trabalho, saberes, gastronomia, vestimenta ou outras tantas. Mas o fator linguístico é um dos pilares para que tais tradições mantenham-se ao longo dos anos.

$\mathrm{O}$ uso da língua materna, junto com os preceitos religiosos, são fundamentais para que a cultura seja repassada entre os membros de comunidades de imigrantes.Manter-se relacionado com a cultura do local de origem é deste modo algo importante. Mesmo que o retorno para uma vivência plena desta identidade cultural seja um sonho distante, ainda mais no caso dos alemães menonitas, em específico, que não têm uma pátria definida em virtude de serem frutos de reimigrações múltiplas.

Sem embargo, nas visitas e a partir dos discursos durante as entrevistas, fica claro que a língua é para os moradores de Colônia Witmarsum uma forma de identificação com a pátria que deu origem ao seu povo, ou seja, a Alemanha. O uso da língua é um elemento importante para a construção da identidade étnica, visto que é por meio dos diálogos estabelecidos e utilizando-se a língua materna que eles se sentem pertencentes a um grupo que compartilha de uma mesma cultura, de uma mesma história e de uma mesma origem.

Para os entrevistados, manter a língua alemã viva no cotidiano da comunidade é uma das formas de manter o patrimônio imaterial que herdaram e uma das maneiras de sentirem-se identificados com as suas raízes. Para além disso, a gastronomia, música, práticas cotidianas, histórias de vida e da imigração compõe o patrimônio imaterial desta comunidade e, por consequência colaboram para a formação de sua identidade.

O mantenimento desta cultura entre as gerações é uma forma de sentirem-se sempre ligados à pátria Alemã e fazer viva as tradições que os caracterizam como descendentes de tal. Em Colônia Witmarsum, percebe-se que o uso da língua alemã ou do dialeto Plaudietsch é uma forma para manter a cultura viva, manter os laços com o país de origem e é até mesmo uma possibilidade de ascensão social e econômica na Alemanha, uma vez que segundo os entrevistados, quando há fluência no idioma muitos membros conseguem boas propostas de emprego naquele país.

A partir do levantamento bibliográfico realizado, das visitas, bem como das entrevistas obtidas para este estudo, pode-se perceber entre os membros da comunidade que nem todos já foram para a Alemanha, tampouco sabem se tão breve conseguirão fazê-lo. Mesmo assim manter os 
costumes da terra natal de familiares imigrantes é de fundamental importância, porque desta forma estão incluídos na história e sentem-se todos pertencentes a um mesmo grupo e a uma mesma realidade.

Estudar a fundo a identidade construída ao longo dos anos por aqueles que ainda não tiveram oportunidade de contato direto com o país emissor é talvez um desafio futuro, haja vista que a identidade destes sujeitos, em específico, é uma construção paulatina e que parte, muitas vezes, de um local e uma realidade imaginada. Mas percebe-se que mesmo com o passar de tantos anos desde a chegada destes imigrantes ao Brasil, busca-se pelos membros da comunidade manter-se ligado à Alemanha, à pátria que deu origem ao seu povo.

Utilizar-se do patrimônio herdado, neste caso, a língua alemã oficial ou ainda o dialeto, é de fundamental importância, porque reconhecem-se como legítimos e aceitos. Os moradores da referida comunidade sentem-se pertencentes à história alemã menonita e toda a sua saga desde os anos 1500, aproximadamente.

Tendo em vista o objetivo inicialmente proposto nesta pesquisa, os conceitos tratados nela, bem como o relato das informações obtidas em campo, pode-se afirmar que o resultado esperado foi alcançado. Foi possível compreender de que maneira o uso da língua materna compõe a identidade étnica dos moradores desta comunidade e também de que maneira isto serve para (re)afirmar tal identidade no contexto de diferença em que vivem.

A pesquisa aqui apresentada não é conclusiva, tampouco única no que diz respeito aos estudos identitários, no entanto, possui relevância por buscar tratar de uma comunidade de imigrantes expressiva no estado do Paraná. Sem embargo, a comunidade de maneira geral coloca-se à disposição de estudos em relação à sua história e origem justamente por entender que fazem parte de uma realidade singular, já que não possuem apego a um território fixo e que, de maneira significativa, contribuem para o avanço das pesquisas relacionadas à cultura, identidade e etnicidade no estado.

Portanto, as reflexões aqui apresentadas intentam ser um ponto inicial de discussão no tocante à identidade étnica em Colônia Witmarsum, uma vez que, a partir das visitas realizadas e também das entrevistas feitas, pode-se perceber as múltiplas possibilidades de olhares que ainda podem ser lançados em relação à temática central abordada.

\section{Notas}

1 Os alemães menonitas fazem parte de um grupo sócio-religioso que provém do movimento anabatista da época da reforma protestante. Apesar de serem de origem holandesa, os menonitas adquiriram cultura alemã pela longa permanência na região de Dantzig.

2 Outras grafias possíveis: Plaudietsch, Plattdeutsch, Plattdüütsch ou abreviada como Plat.

3 (...) las artes y las letras, los modos de vida, los derechos fundamentales al ser humano, los sistemas de valores, las tradiciones y las creencias. (UNESCO, 1982: 39).

4 Reimigrante: aquele que migra por mais de uma vez ou que volta ao país de origem e uma vez mais retoma o processo migratório.

$5 \mathrm{Um}$ dos fundadores do movimento anabatista, cujo nome serve de referência deu origem ao termo menonita. A fé com base nos preceitos bíblicos era pregada nas regiões da Frísia, Sul da Holanda e Alemanha, visando a criação de uma igreja livre, pacifista e desvinculada de governos.

\section{Referências}

ASSOCIAÇÃO $\quad$ COMUNITÁRIA
MORADORES DOS
WITMARSUM (ACMPW) - Site institucional.
Disponível em http://www.acmpw.com.br/. Último
acesso em 06/11/2015.
. (2001). Witmarsum, 50 anos no Paraná: A história da colônia, a atuação menonita e os pioneiros. s/c. s/e.

CARDOSO DE OLIVEIRA, Roberto. (2006). Caminhos da identidade: ensaios sobre a etnicidade e multiculturalismo. São Paulo: UNESP.

CARDOZO, Poliana. (2012). O Líbano Ausente e o Líbano Presente: espaço de identidades de imigrantes libaneses em Foz do Iguaçu. Tese de Doutorado. Curitiba: Universidade Federal do Paraná (UFPR). 
CLAVAL. Paul.(2001). A geografia cultural. $2^{\mathrm{a}}$ ed. Florianópolis: UFSC.

CUCHE, Denys. (2002). A noção de cultura nas ciências sociais. Bauru: Edusc.

ENNS, Egon Robert. CAMARGO, Marco A. Ribeiro de. KRÜGER, Adolf. (2000). Permanecei em mim: 70 anos da imigração menonita. Curitiba: s/e.

GRÜNEWALD, Rodrigo. (2003). Turismo $e$ etnicidade. Horizontes Antropológicos: 141-159. Disponível em http://www.scielo.br/pdf/ha/v9n 20/v9n20a07.pdf. Último acesso em 06/11/2015

KLOSTER, Silvana. (2013). Riscos $e$ potencialidades da atividade de turismo rural na microrregião de Ponta Grossa. Dissertação de Mestrado. Ponta Grossa: Universidade Estadual de Ponta Grossa (UEPG).

LARAIA, Roque de Barros. (2007). Cultura: um conceito antropológico. 21 ed. Rio de Janeiro: Jorge Zahar.

ORGANIZAÇÃO DAS NAÇÕES UNIDAS PARA A EDUCAÇÃ̃O, CIÊNCIA E TECNOLOGIA. Site institucional. Disponível em www.unesco.org. Ultimo acesso em 06/11/2015.

PAULS, Peter. (2010). "Witmarsum para conhecer e gostar". In: SIEMENS, Udo. (org.). Quem somos? 1930-2010: A saga menonita rompendo a barreira cultural. $1^{\text {a }}$ ed. Curitiba: Editora Evangélica
Esperança.

POUTIGNAT, Philippe. STREIFF-FENART, Jocelyne. (2011). Teorias da etnicidade: seguido de grupos étnicos e suas fronteiras de Fredrik Barth. Tradução Elcio Fernandes. 2. ed. São Paulo: Unesp.

SANTAYANA, Mauro. (2002). "O século XXI e o desafio das etnias". In: SANTOS, Milton et al (Org.). Território: globalização e fragmentação. 5. ed. São Paulo: Hucitec, 2002.

SILVA, Rosijane Evangelista da. CARVALHO, Karoliny Diniz. (2010). Legados étnicos, turismo e sustentabilidade: um olhar sobre a comunidade quilombola de Filipa, Maranhão. Caxias do Sul: Anais do VI Seminário de Pesquisa em Turismo do Mercosul.

SOARES, Joélcio G.(2013). "Turismo na Colônia Witmarsum, Palmeira/PR: fomento externo e estrutura interna". In: LLERA, Francisco J.. BAUTISTA, Elizabeth. (coords.) Comunidades Menonitas de México y Brasil: Influencia y Aportaciones. Ciudad Juárez: Universidad Autónoma de Ciudad Juárez.

ZUGUEIB, Jamil Neto. (2005) "Identidades e crises sociais na contemporaneidade" - prefácio. Ed. UFPR: Curitiba.

WITMARSUM COOPERATIVA. Site institucional. Disponível em http://www.witmarsu m.coop.br/. Último acesso em 06/11/2015.

\section{Sobre as autoras}

Carla Caroline Holm é Bacharel em Turismo e Mestre em Desenvolvimento Comunitário pela Universidade Estadual do Centro-Oeste (UNICENTRO). Pesquisa nas temáticas sobre turismo, desenvolvimento comunitário, cultura, identidade, e patrimônio cultural.

Poliana Fabíula Cardozo é Bacharel em Turismo pela Universidade do Oeste do Paraná (UNIOESTE), Mestre em Turismo pela Universidade de Caxias do Sul (UCS) e Doutora em Geografia pela Universidade Federal do Paraná (UFPR). Pesquisa nas temáticas sobre turismo, cultura árabe e preservação cultural. 
Recebido em fevereiro de 2015.

Aprovado em novembro de 2015.

Horizontes, v. 33, n. 2, p. 89-98, jul./dez. 2015 